Makale türü / Article type: Araştırma / Research

\title{
Artan Küresel Isınma ve Duyarsızlaşan Küresel Politikalar
}

\section{Increasing Global Warming and Glazing Global Policies}

\author{
Dr. Öğr. Üyesi Hasan Eryılmaz \\ Artvin Çoruh Üniversitesi, Mühendislik Fakültesi, Çevre Mühendisliği Bölümü, \\ h.eryilmaz@artvin.edu.tr: (ORCID: 0000-0003-4909-6907) \\ Dr. Öğr. Üyesi Kazım Onur Demirarslan \\ Artvin Çoruh Üniversitesi, Mühendislik Fakültesi, Çevre Mühendisliği Bölümü, \\ onurdemirarslan@artvin.edu.tr: (ORCID: 0000-0002-1023-7584)
}

\begin{abstract}
Özet
Günümüzde tüm dünya teknolojiye ve sanayiye bağımlı bir hale gelmiş bulunmaktadır. Bu bağımlılığın faturası da ne yazık ki doğaya kesilmekte ve sonuç olarak gelecek nesillerin yaşamından çalınmaktadır. Yaşanan bu olumsuzlukların nedeni, sanayileşme ve çevre kirliliği olarak söylenebilir. Modern yaşamımızı devam ettirebilmemiz için atmosfere devamlı olarak $\mathrm{CO}_{2}$ salınımı yapmaktayız. Tüm bu salınım sonucunda atmosfer etkilenmekte; bu durum da küresel isınmaya neden olmaktadır. Atık su, katı atıklar ve tehlikeli atıklar gibi çevre problemlerinin pahalı da olsa çözümleri olmasına karşın atmosfere salınan $\mathrm{CO}_{2}$ 'yi azaltabilecek ve/veya giderebilecek herhangi bir konvansiyonel sisteme sahip olmayışımız bu önemi bir kat daha arttırmaktadır. Dünya ülkeleri $\mathrm{CO}_{2}$ salınımını azaltacak tedbirler alarak bu soruna çözüm bulmak istemişlerdir. Ancak birtakım ülkeler ise kendi çıkarlarını gözettiklerinden bu konuya yanaşmamışlardır. Yapılan bu çalışmada $\mathrm{CO}_{2}$ salınımının dünya üzerindeki yansımaları, ülkeler ve anlaşmalar çapında incelenmiş, literatüre önemli bir kaynak olması amaçlanmıştır.
\end{abstract}

Anahtar Kelimeler: $\mathrm{CO}_{2}$, Küresel Isınma, Küresel Politikalar, Sera Gazı

JEL Sınıflandırması: Q28, Q38, Q54

\begin{abstract}
Nowadays, the world has become addicted to technology and industry. Unfortunately, the consequence of this kind of dependency cut off to nature and is eventually stolen from the lives of future generations. The reason for these negativities can be said as industrialization and environmental pollution. $\mathrm{CO}_{2}$ has been constantly release to the atmosphere to continue our modern life. Thus, the atmosphere has been badly affected
\end{abstract}


with this $\mathrm{CO}_{2}$ emission which causes global warming. Although environmental problems such as wastewater, solid wastes and hazardous wastes have costly solutions, we do not have a conventional system to reduce andlor compensate $\mathrm{CO}_{2}$ emission in the atmosphere. So, this makes the importance of this subject more crucial. The world countries wanted to take some precautions to reduce the $\mathrm{CO}_{2}$ emission, but some countries have not even considered these precautions due to their own countries interest. In this study, the reflections of $\mathrm{CO}_{2}$ emissions around the world have been investigated in terms of countries and agreements, and it is aimed to be an important source in the literature.

Key Words: $\mathrm{CO}_{2}$, Global warming, Global policies, Greenhouse gases

JEL Classification: Q28, Q38, Q54

\section{GİRIŞ}

Dünya atmosferinde başta karbondioksit olmak üzere, sera gazlarının konsantrasyonları giderek yükselmekte ve buna bağlı olarak da dünya atmosferi de giderek 1sınmaktadır. Buna rağmen yaklaşık iki yüz yıldır dünya atmosferini kirleten gelişmiş ülkeler, tarihi sorumluluklarından kaçıp kurtulmanın yollarını aramaktadırlar. Günümüzde ABD' nin yeni başkanı Donald Trump, eski başkan Barack Obama'nın iklim değişikliği ile mücadele kapsamında uygulamaya koyduğu çevre düzenlemelerini fiilen kaldıran bir kararnameyi imzalamış bulunmaktadır. Trump, EPA 'nın 2018 bütçesinde \%31'lik bir kesinti yaparken, iklim değişikliğiyle mücadeleye ayrılan fonların neredeyse tamamını kesmiş ve "Madencilerimizi tekrar iş başına döndüreceğiz ve gerçekten temiz kömür üreteceğiz" açıklamasını yapmıştır (URL-1).

Trump, Paris İklim Anlaşmasından çekilme kararı almış ancak; AB, Rusya, Hindistan ve Çin'den anlaşmaya destek açıklamaları gelmiştir (URL2). Böylelikle kaşla göz arasında 2016 yılında Çin üretime aldığı beş nükleer santral (NES) sayesinde de NES kaynaklı enerji üretimini \%25 arttırmış olmuştur (Şahin, 2017). Paris Anlaşması hükümleri gereği ise çekilme işlemlerinin, ancak 4 Kasım 2020' de tamamlanacağı belirtilmektedir.

Paris anlaşmasına bakıldığında reddeden ülke sayısının ABD-SuriyeNikaragua ile birlikte üç olduğu anlaşılmaktadır. Halen küresel emisyonun 
\%14'ünü oluşturan $\mathrm{ABD}$, tarihsel toplam emisyon oranında en büyük paya sahip olmasına karşın 75 ABD şehri, Paris anlaşmasına uyacaklarını açıklamışlardır (URL-3). Bunun yanında TESLA, GE, Apple, Bloomberg başta olmak üzere birçok şirket, Trump'ın kararına karşı çıktıklarını bildirmişlerdir.

Trump, Paris İklim Anlaşmasından çekilme gerekçesi olarak, anlaşmanın diğer ülkelere, ABD'ye karşı ekonomik avantaj sağlamasını gösterse de ABD' de güneş enerji santralleri (GES)'nde çalışanların sayısının, kömür santrallerinde çalışanların iki katına ulaştığı görülmektedir. Halen Hindistan'da GES elektrik fiyatı, kömür santrali elektrik fiyatından $\% 18$ daha ucuzdur (URL-4).

Görüldüğü gibi GES elektrik fiyatları, şimdiden dünyada yer yer daha ucuz hale gelirken ve fotovoltaik pil panelleri her y1l ortalama \%10 daha ucuzlarken, $\mathrm{ABD}$ için ekonomik rekabetin kaybolduğunu söylemek doğru değildir. Trump ve daha başka birçok liderin küresel ısınmayı bildikleri, başlangıçta bilmeseler de bilgilendirildikleri, ancak bu çok önemli tehlikeyi önemsemedikleri görülmektedir. Bu çalışmada küresel 1sınmayı bir bilimselmasal gibi görenlere karşı, bunun bilim kurgu bir masal değil yaklaşan gerçek bir felaket olduğu, daha somut daha görünür örneklerle ortaya konması amaçlanmıştır.

\section{ATMOSFERDEKİ SICAKLIK ÖLÇÜMLERİ ve DEĞERLENDİRILMESI}

18. yüzy1lda sanayi devrimi ile birlikte artmaya başlayan hava ve çevre kirliliğgi, tüm dünyayı ilgilendirdiği için, mücadele de uluslararası iş birliğini gerektirmektedir. İlk Uluslararas1 Meteoroloji Kongresi Viyana'da 1873'de gerçekleştirilmiş ve bundan sonra da sürekli ölçümlere başlanılmıştır (Erol, 2008):

\footnotetext{
$\checkmark 1880$ yılından beri, atmosfer sicaklığı,

$\checkmark 1958$ yılından beri, atmosferdeki $\mathrm{CO}_{2}$ seviyesi,

$\checkmark 1993$ y1lından beri, deniz seviyesi yükselmesi,
} 
$\checkmark 2002$ yılından beri, kutuplarda buzul kayıpları GRACE uydusu yardımıyla,

$\checkmark 2014$ y1lından beri, NASA OCO-2 uydusuyla günlük binlerce $\mathrm{CO}_{2}$ değeri ölçülmektedir.

Ölçüm sonuçlarının artmasıyla beraber tehlike de fark edilmeye başlanmıştır. 1972'de Stockholm'de toplanan ilk BM Çevre Konferansı ardından, 1979'da Cenevre'de WMO tarafindan 1.Dünya İklim Konferans1 gerçekleştirilmiştir. 1988'de ise WMO, UNEP ve UNESCO'nun işbirliği ile Birleşmiş Milletlere bağlı UN-IPCC (Intergovernmental Panel on Climate Change) kurulmuştur. IPCC, Birleşmiş Milletler adına 85 ülkeden yaklaşık 2000 kadar iklim uzmanıyla, dünyadaki iklim ile ilgili bütün çalışmaları toplayan, inceleyen ve sonra raporlaştıran uzman bir kuruluş olarak tanımlanabilir. Bugüne kadar IPCC tarafından 1990, 1995, 2001, 2007, 2013 yıllarında 5 ayrı rapor yayınlanmıştır. 2013'deki sonuncu raporu AR5'de, küresel iklim değişiminin \%95 oranında insan kaynaklı olduğunu ortaya koymuştur (REC Türkiye, 2015).

IPCC' nin ortaya koyduğu raporların, etkisini ve konunun aciliyetini göstermeye başlamasının ardından, 1990'da yayınlanan FAR (birinci değerlendirme raporu) ve $1995^{\prime}$ de yayınlanan SAR (ikinci rapor) ile birlikte, konuyu devlet başkanları düzeyinde değerlendirmek için konferanslar başlatılmış ve 1995 'de Berlin'de ilk COP 1 (Conference of Parties) toplanmıştır. 1997'de Japonya-KYOTO 'da toplanan COP 3'de, sera gazları olarak $\mathrm{CO}_{2}, \mathrm{CH}_{4}, \mathrm{~N}_{2} \mathrm{O}$, PFC (perflorokarbonlar), $\mathrm{HFC}$ (hidroflorokarbonlar), $\mathrm{CFC}$ (kloroflorokarbonlar), $\mathrm{SF}_{6}$ (kükürthegzaflorür) gazları belirlenmiş (REC Türkiye, 2015) ve ardından Kyoto Protokolü (KP) imzalanmıştır. Ancak daha sonra ABD ve Çin Kyoto Protokolünden çekilmişlerdir. ABD, 2000'de Lahey'de toplanan COP 6'da da Kyoto Protokolünü reddetmeyi sürdürmüştür. Kyoto Protokolünün yürürlüğe girmesi ancak 2005 'de Montreal'de toplanan COP 11'de 55 ülkenin imzasıyla mümkün olabilmiştir. İlk defa Kopenhag'da 2009 yılında toplanan COP15'de, küresel ssınma için maksimum $2^{\circ} \mathrm{C}$ hedefi konmuş olmasına karşın nasıl olacağı belirlenememiştir. IPCC' nin 2013'deki beşinci raporu AR5'in ardından, 2014'de Lima'da yapılan COP20'de, o 
zamana kadar yapılan sera gazı emisyonları azaltım çalışmaları gibi, küresel ısınmanın getireceği risk ve tehlikelere karşı uyum çalışmalarının da çok önemli olduğu kabul edilmiş ve bu yönde araştırmalara hız verilmiştir. Nihayet 1-12 Aralık 2015'de Paris'te yapılan COP 21 zirvesinde ABD de dâhil 195 ülkenin oy birliği ile küresel 1sınma için 2100 yılı sonu olarak 1,5 ${ }^{\circ} \mathrm{C}$ ve eğer isınma bir şekilde engellenemeyerek bu değeri geçerse, maksimum $2^{\circ} \mathrm{C}$ hedefi kabul edilmiştir. Bunu sağlamak için gelişmiş ülkeler tarafindan gelişmekte olan ülkelere teknoloji ve finansman desteği verilecekti. Ancak ABD’nin itirazıyla anlaşma bağlayıcı olmaktan çıkarıldı ve gönüllülük esas alındi.

Anlaşmaya göre, uygulamanın sürekli olarak takip edilmesi, ilk raporun 2025 'de hazırlanması nedeniyle süreç içinde ülkelerin emisyonları devamlı azaltılırken, 2050 sonrası hızla düşürülmesi planlanmaktaydı. Paris İklim Anlaşması'nın pek çok detayı varsa da göze çarpanlar aşağıdaki gibi özetlenebilir:

$\checkmark$ ABD, Çin, Almanya, Fransa, İngiltere, Hindistan dâhil 20 ülke, iklimle ilgili "Mission Innovation" projesi için ARGE bütçelerini ikiye katlayacak, 2020’ye kadar 20 milyar \$ koyacak olup; 2023 sonrası da 100 milyar \$ üzerinde katkıda bulunulacak,

$\checkmark$ Bill Gates, Mark Zuckerberk, Jeff Bezoz gibi 280 milyarder tarafından, iklim çalışmaları 2 milyar \$ desteklenecek,

$\checkmark$ İstanbul dâhil 1000 belediye başkanı 2050’ye kadar \%100 yenilenebilir enerjiye geçecek,

$\checkmark$ Merkezi ABD, genel müdürlüğü Çin'de olarak kurulan GSC (Global Solar Council)'de Fransa ile Hindistan öncülügüünde 100'den fazla ülke, daha etkin ve ucuz GES teknolojisi için işbirliği yapacaklar,

$\checkmark$ Türkiye'yi de çok yakından ilgilendiren, Çin-Avrupa İpekyolu Elektrikli Tren Yolu Projesi gerçekleştirilecek.

Paris İklim Anlaşması imzaya açılarak, Türkiye de dâhil olmak üzere 194 ülkenin imzası ve 127 ülkenin taraf oluşuyla yürürlüğe girdi. Taraf olanların sayısı halen 149'a ulaşmasına rağmen, Rusya'nın henüz taraf 
olmadığ1 görülmektedir. Türkiye anlaşmayı imzalamasına karşın bir yükümlülük altına girmemek için taraf olmamış, ancak diğer ülkeler gibi, gönüllü olarak sera gazları emisyonunu azaltmak için "Ulusal Katkı Niyeti" (INDC: Intended Nationally Determined Contribution) raporunu BM'ye sunmuştur. Buna göre 2030'a kadar sera gazı emisyonlarımızı 2015 y1lı değerlerinin değil, şimdiki artış hızına göre 2030 yılında ulaşacağı hesaplanan ve daha yüksek olan toplam emisyon değerlerinin \%21 altına, gönüllü olarak düşüreceğimiz öngörülmektedir.

Tüm bu gelişmelere rağmen $\mathrm{ABD}$, yeni Başkan Trump ile birlikte önceki müzakerelerde olduğu gibi yeniden bozgunculuğa başlamış ve 2017 yılı Haziran ayı başında Paris İklim Anlaşması'ndan çekilme kararı almıştır.

Yukarıdaki kısa tarihçe bile, küresel ısınmanın bilim kılıflı uydurulmuş bir masal olmadığını göstermektedir. Zaten 1989'da o zamanki İngiltere Başbakanı Margaret Thatcher $\mathrm{CO}_{2}$ azaltımına karşı çıkarak, 1990'da ABD kömür ve petrol tröstleri "Küresel İklim Koalisyonu" kurarak ekonomik avantajın kaybı bahanesiyle iklim çalışmalarına karşı kampanyalar başlatmışlardı. Bugün $\mathrm{CO}_{2}$ salınımında dünya birinciliğini Çin'e kaptırmış olsa da 1990'da ABD \%36 salınım ile birinci olmuştu. Şimdi yeni başkanla birlikte 1990’lı yılların politikalarına tekrar dönmüş bulunmaktadır.

\section{2. İKLİM DEĞISŞIKLİĞİ VE KÜRESEL ISINMANIN VERİLER IŞIĞINDA DEĞERLENDİRILMESI}

Artan Sicaklıklar:

$\checkmark$ NASA, WMO (World Meteorological Organization) ve Met Office (İngiltere) kayıtlarına göre 2016 yılı, üst üste sıcaklık rekorları kırılan üçüncü yıl olmuştur (URL-5).

$\checkmark$ 1880'den beri tutulan kayıtlar içinde 2015 y1lı en sicak y1l olmuş, küresel atmosfer sıcaklığ $14,79{ }^{\circ} \mathrm{C}$ olarak kayıtlara geçmiştir. Hâlbuki 2000 yılında atmosfer sıcaklığ $14,45^{\circ} \mathrm{C}^{\text {‘ }} \mathrm{ydi}$ (URL-1).

$\checkmark$ 1906-2005 arası 20.yüzyıl küresel sıcaklık artışı $(0,74 \pm 0,18)^{\circ} \mathrm{C}$ olarak belirlenmiştir (IPCC, 2007). 
$\checkmark$ Sıcaklıkların atmosferdeki $\mathrm{CO}_{2}$ miktarı ile doğru olarak sürekli arttığı belirtilmektedir.

Ulusal Okyanus ve Atmosfer Kuruluşu (National Oceanic and Atmospheric Administration) resmi internet sitesinden 1959-2016 y1lar1 $\mathrm{CO}_{2}$ artış oranları verilerinden yararlanılarak yıllık $\mathrm{CO}_{2}$ artış miktarı belirlenmiş ve Şekil 1' deki grafikte verilmiştir (URL-6). NASA'nın resmi internet sitesinden alınan yıllık sıcaklık değişim verileri ile oluşturulan grafik ise Şekil 2' de verilmektedir (URL-7). Şekil 1 ve 2'deki veriler mutlak olmayıp sadece artı̧̧ verilerini ifade etmektedir.

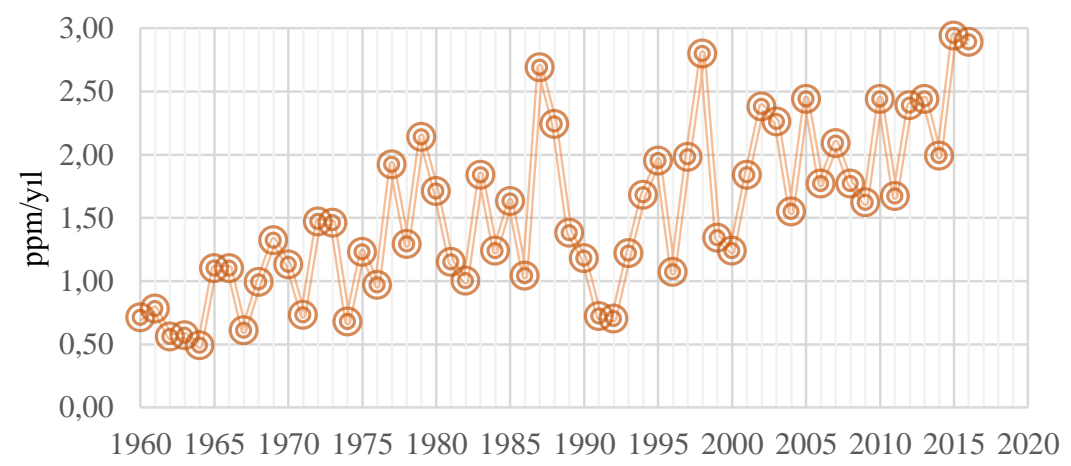

Şekil 1. 1959-2016 y1lları, yıllık $\mathrm{CO}_{2}$ artışları

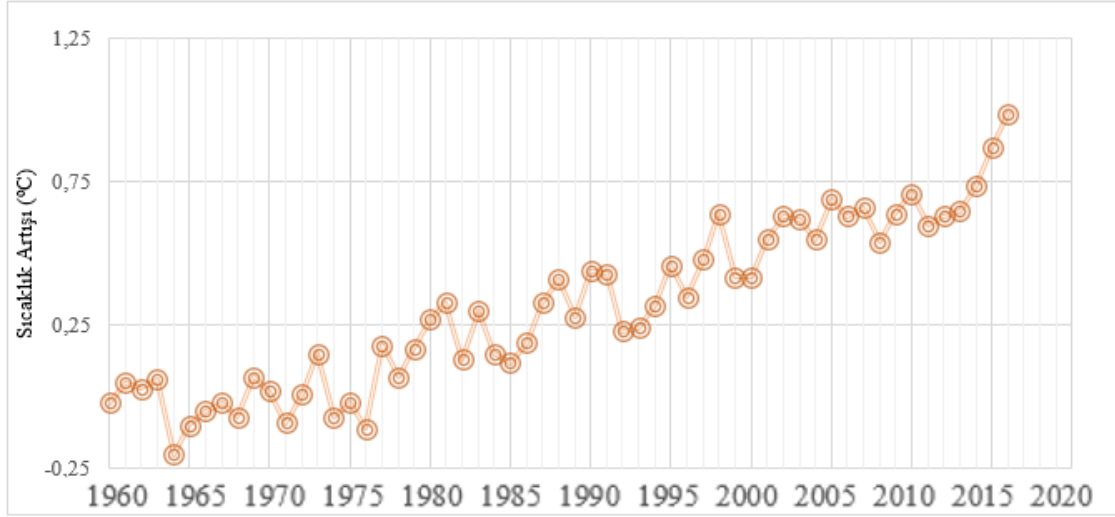

Şekil 2. 1959-2016 yılları, yıllık sıcaklık artışları

Şekil 1 ve 2' de, 1970'li ylllardan itibaren hem atmosferdeki $\mathrm{CO}_{2}$ miktarının hem de atmosfer sıcaklığının arttığı, 1990'lardan sonra artışın daha 
da hızlandığı görülmektedir. Büyük Okyanus'ta, Mauna Loa Observatory gözlem istasyonunda, Haziran 2016'da 406 ppm olan atmosferdeki $\mathrm{CO}_{2}$ konsantrasyonu, Nisan 2017'de 413 ppm' lik rekor bir değere ulaşmıştır. (URL-8). Küresel 1sınma (1901-2012) yılları aras1 112 y1l için 0,89 ${ }^{\circ} \mathrm{C}$ (IPCC, 2013) olarak belirtilmiştir. Bu değerden yukarıda verilmiş olan IPCC 2007 AR4 raporunun (1906-2005) yılları arası artışı gösteren $0,74^{\circ} \mathrm{C}$ farkı alınırsa (0,89-0,74=0,15), 2005'den 2012'ye kadar geçen 7 yll içinde küresel sıcaklığın $0,15^{\circ} \mathrm{C}$ arttığ 1 ortaya çıkar ki bu da son 10 yıl için $0,21^{\circ} \mathrm{C}$ artış demektir. AR4 raporundaki $0,74{ }^{\circ} \mathrm{C}$ değeri ise, 20. yüzyıldaki 10 yıl başına ortalama artışın $0,074{ }^{\circ} \mathrm{C}$ olması demektir. Görüleceği üzere 0,21 değeri 0,074 değerinin 2,8 katıdır. Yani küresel 1sınma hızı, önceki yıllara göre 2,8 daha artmıştır.

Sondan bir önceki değer, NOAA 'dan: 1880'den 2017'ye kadar (2017 hariç) küresel sıcaklık artış1 0,94 ${ }^{\circ} \mathrm{C}$ (URL-9), ve son değer ise, NASA 'dan: 1880 'den günümüze kadar artış $0,99^{\circ} \mathrm{C}$ olarak verilmiştir (URL-10).

\section{Eriyen Buzullar:}

Artan sıcaklıklar, binlerce yıldır birikmiş kutup buzulları ve yüksek dă buzullarının erimesini de hızlandırmaktadır. Dünyada bu konuyla ilgili yaşanmış pek çok örnek bulunmaktadır (URL-11). 


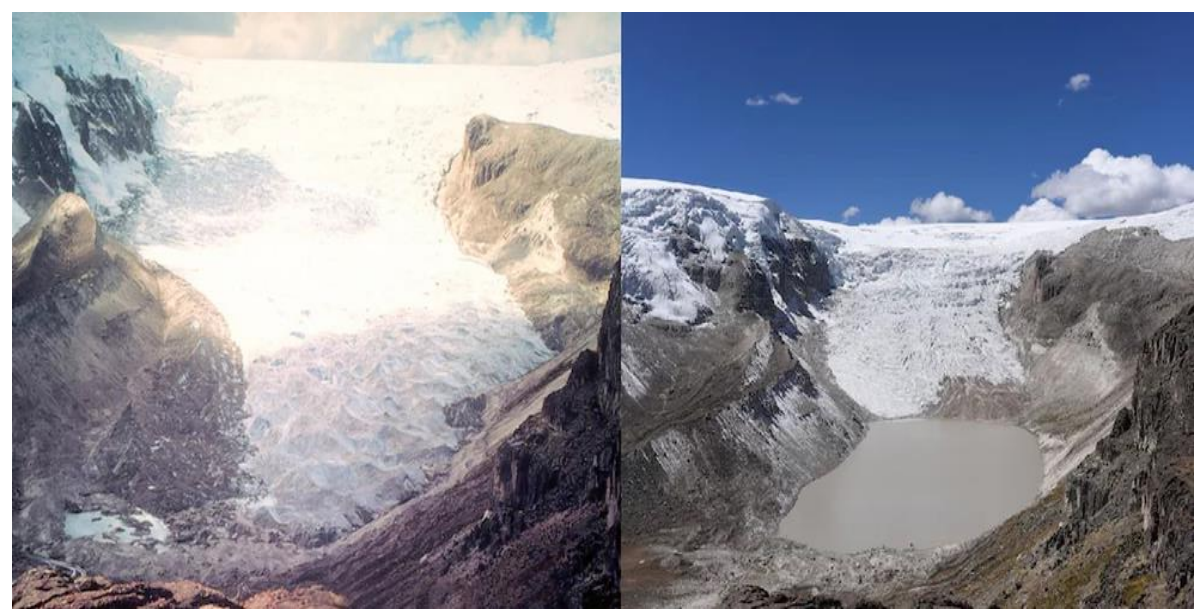

Şekil 3. Peru'daki Qori Kalis Buzulu 1978 (sol) ile 2016 (sağ) arasındaki 1,14 km'lik fark.

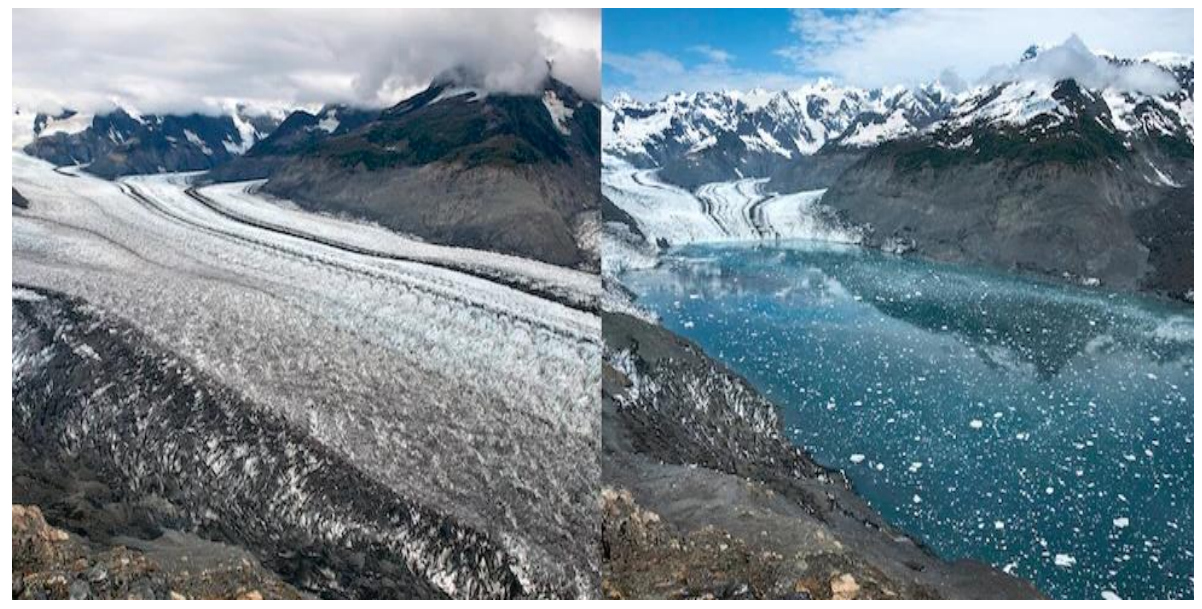

Şekil 4. Alaska'daki Columbia Buzulu, 2009 (sol) ile 2015 (sağ) arasındaki 6,5 km'lik fark. 


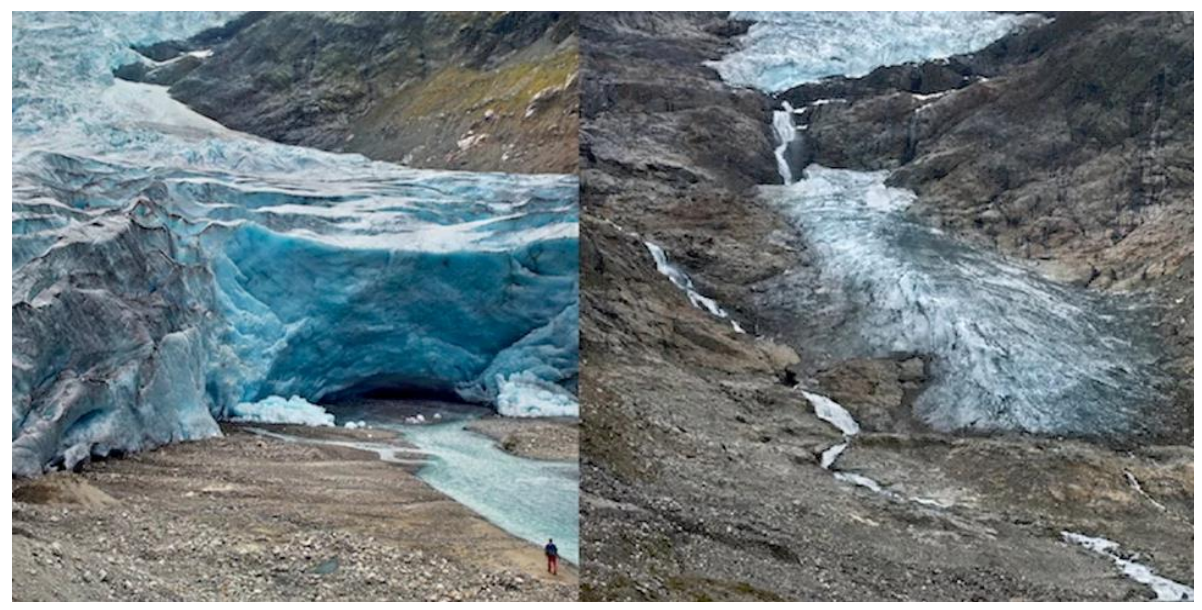

Şekil 5. İsviçre'deki Trift Buzulu, 2006 (solda) ile 2015 (sağda) arasındaki 1,17 km'lik fark.

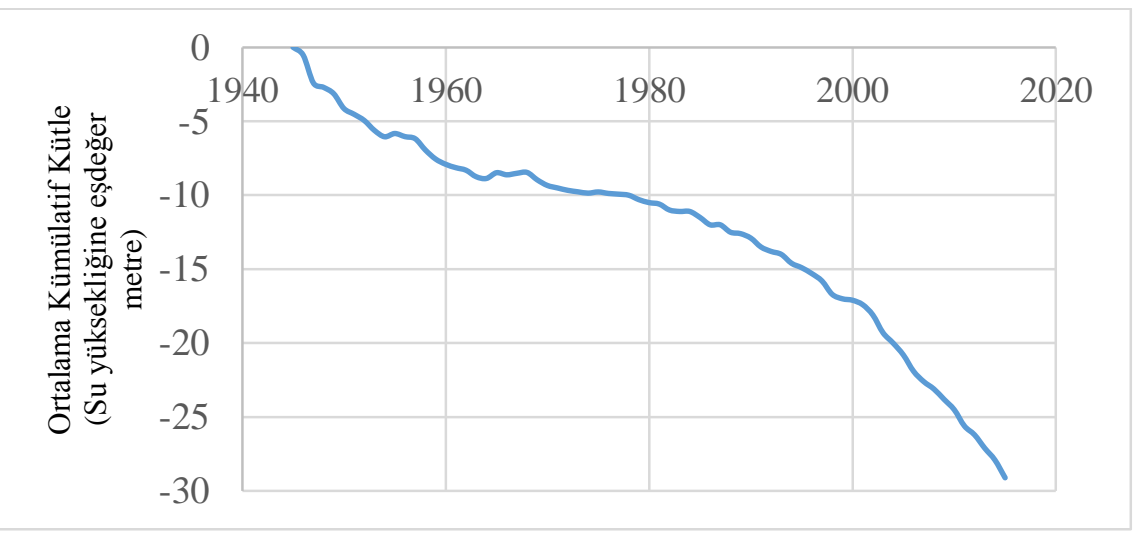

Şekil 6. Dünya genelindeki 1945-2015 yılları arası "Referans" Buzulların Kümülatif Kütle Dengesi

Şekil 6' da 1945'ten başlayarak dünya çapında bir "referans" buzul grubunun kütle dengesindeki kümülatif değişimi görülmektedir. Negatif değerlerde, 1945 yılının tabanına kıyasla net bir buz ve kar kayıpları olduğunu göstermektedir. Tutarlılık için, ölçümler bir buzulun ortalama kalınlığındaki değişiklikleri temsil eden su eşdeğeri metre cinsindendir (URL-12). 
Tüm bu örneklerin yanında Tablo 1'de siralanan olaylar da görülmüştür.

Tablo 1. Olgular ve Olaylar: Değişen Küresel İklim Üzerine Değerlendirmeler.

\begin{tabular}{|c|c|}
\hline Olgu ve Olaylar & Yorum ve Değerlendirme \\
\hline $\begin{array}{l}\text { Grönland buzullarının eriyip } \\
\text { çekilmesiyle, yeni bir ada ortaya } \\
\text { çıktı. 1985'de tamamen anakaraya } \\
\text { bağlı ve örtülü, } 2002 \text { ‘de ince bir } \\
\text { buz tabakasıyla anakaraya bağlı, } \\
2005 \text { 'de tamamen ayrı bir ada } \\
\text { (URL-13). }\end{array}$ & $\begin{array}{l}\text { Buzulların erimesi, küresel ölçekte } \\
\text { denizlerin yükselmesine sebebiyet } \\
\text { verebilir. Bu da okyanus ve deniz } \\
\text { kenarlarında bulunan kentlerin su } \\
\text { altında kalan alanlarının } \\
\text { miktarlarında artışa neden } \\
\text { olacaktır. }\end{array}$ \\
\hline $\begin{array}{l}\text { Antarktika'da buzul erime hızı, } \\
\text { (2005-2010) yıllarına göre (2010- } \\
\text { 2013) yıllarında iki katına çıktı } \\
\text { (URL-5). }\end{array}$ & $\begin{array}{l}\text { Bu durum küresel ısınmanın } \\
\text { giderek hızlandığını göstermektedir } \\
\text { ve günümüzün en büyük çevresel } \\
\text { problemidir. }\end{array}$ \\
\hline
\end{tabular}

NASA, buzulları izleyen GRACE Buzulların erimesi, küresel ölçekte uydusu verilerine göre, Grönland ve Batı Antarktika'nın her yıl yaklaşık 150 km³ küçüldüğünü ve Kuzey Buz Denizi'nin (1980denizlerin yükselmesine sebebiyet verebilir. Bu da okyanus ve deniz 2005) arasında \% 20 alan kenarlarında bulunan kentlerin su altında kalan alanlarının kaybettiğini açıkladı (Hansen, miktarlarında artışa neden 2009). olacaktır.

Hakkari-Cilodağı'nın Uludoruk buzulu, 1940'da 2600 m yükseklikte başlarken, 1991 'de 3000 m yükseklikten sonra başlıyor. Yaklaşık $400 \mathrm{~m}$ kadar eriyerek çekilmiş (Şen, 2009).
Bu durum Türkiye'deki küresel 1sınmanın etkisini göstermektedir. Özellikle yaz mevsimi için su kaynaklarının azalması ve sulama ile yapılan tarımsal üretimin azalması demektir. 
Kayseri-Erciyes buzulu 1905 'de

3100 m'de başlarken, 2002'de

3420 m'den başliyor, o zaman için

$320 \mathrm{~m}$ eriyerek çekilmiş (Şen,

2009).

Kafkas Buzulları (1895-2000)

arasinda \% 43 alan $\% 56$ hacim

kaybetti (Şen, 2009).

Deniz Seviyesi Yükselmesi ve Batan Adalar:

$\checkmark$ IPCC 2013 AR5'e göre (1901-2010) yılları aras1 110 yılda dünya deniz seviyesi ortalama $19 \mathrm{~cm}$ yükseldi.

$\checkmark$ Amerikan Ulusal Bilimler Dergisi PNAS araştırmasına göre, ortalama deniz seviyesi, okyanusların 1sınması ile yer yıl 1,4 mm ve buzulların erimesi ile de birlikte $2,7 \mathrm{~mm}$ artmaktadır. Ancak Batı ABD'de seviye sabit kalırken, Filipinler'de artış 5 kata ulaşmaktadır (URL-14).

$\checkmark$ Denizlerde seviye yükselmesi de giderek hızlanıyor. IPCC 2007 AR4 raporuna göre, (1961-2003) arası yıllık artış 1,8 mm iken (1993-2003) arası 3,1 mm'yi bulmaktadır.

$\checkmark$ Pasifik Okyanusu'nda, Kribati mercan adalarını su basmıştır. Adalarda yaşayan yaklaşık 100 bin insan sular yükseldikçe Tarawa adasına göç etmektedirler (URL-14).

$\checkmark$ Pasifik'te Solomon Adaları'nda (1947-2014) yılları aras1 5 ada tamamen kayboldu ve 6 ada \% 20-62 arası toprak kaybetti. Bölgede deniz seviyesi her y1l 7 mm yükselmektedir (URL-15).

Küresel Isınmanın Meydana Getirdiği Önemli Bazı Olaylar:

$\checkmark$ Artan atmosfer sıcaklığı dünya iklim kuşaklarını da hareketlendirmektedir. Sicaklık izotermleri, 10 yıl başına (19501995) yılları arasında $12 \mathrm{~km}$ kuzeye doğru, dağlarda ise $12 \mathrm{~m}$ 
yükseğe doğru kaydığı belirlenmiştir. Şimdi bu değerler $56 \mathrm{~km}$ kuzeye 29 m yükseğe olarak değişmiştir. Bu iklim kaymasına paralel olarak, hayvanlar kolay uyum gösterip kayarken, bitkiler aynı hızla kayamamakta ve gıda kaynaklarından uzak kalan hayvan türleri yok olmaktadır. Yırtıcı hayvanların kayması 10 yılda ortalama $50 \mathrm{~km}$ iken ormanların kayması sadece $15 \mathrm{~km}$ kadar gerçekleşmektedir (Hansen, 2009).

$\checkmark 2011$ y1lında son Javan Gergedanı Vietnam'da, son siyah Batı Gergedanı'da Kamerun'da tükenmiştir. Goriller ise Gambia, Burkina- Faso, Benin ve Togo yabanlarından tamamen silinmişlerdir (URL-16).

$\checkmark$ Artan sıcaklıklar, artan buharlaşmayla birlikte, belli bölgelerde kuraklık ve çölleşmeyi arttırırken, belli bölgelerde de aşırı yağışları, sel baskınlarını ve toprak kaymalarını arttırmaktadır. Artan kuraklık, Dünya 'da 4 milyar hektar alanı ve 1,2 milyar nüfusu doğrudan tehdit ediyor ve her y1l 6 milyon hektar hızla, çölleşme artıyor (URL-17).

$\checkmark$ 20.yüzyılda yağışlar, tropik bölgelerde \% 3 azalırken, kuzey bölgelerde \% 5-10 artmıştır (IPCC-TAR, 2002).

$\checkmark$ Mayıs 2014'de Doğu Avrupa ve Balkanlar'da aşırı sellerden yaklaşık 2000 heyelan meydana geldi (AÇA, 2015).

$\checkmark$ Artan sıcaklıklar Avrupa'da orman yangınlarını arttırarak (yaklaşık 70000 yangın) hastalıklı ve böcekli ormanların 1990'ların iki katına çıkmasına neden olmuştur (AÇA, 2015).

$\checkmark$ Son 5 yılda dünyadaki orman kaybı, 29 milyon hektar olarak kayıtlara geçmiştir (Karapınar, 2016).

$\checkmark$ Artan sıcaklıklar ile deniz suyunda $\mathrm{O}_{2}$ çözünürlüğü azalırken, var olan az miktar $\mathrm{O}_{2}$ 'in tüketimi de hızla artmaktadır. Her y1l artan kanalizasyon artıkları ile birlikte net sonuç; aşırı ötrofikasyon ve deniz çöllerinin oluşumudur. 1950'den beri küresel ölü deniz alanları, her 10 yılda iki katına çıkmıştır (AÇA, 2015). 
$\checkmark$ Kuzey Denizi'nde eskiden morina balığı yakalayan balıkçılar, şimdilerde karides ve salyangoz avlamaktadırlar (Hansen, 2009).

\section{SONUÇ}

$\mathrm{Bu}$ çalışmada anlatılanlardan çıkacak net ve özet sonuç, "Dünya atmosferinin sürekli isındığı"dır. Atmosferdeki $\mathrm{CO}_{2}$ konsantrasyonu önceki bölümde geçtiği gibi 2017'de 413 ppm'e ulaşmıştır. Diğer sera gazlarının konsantrasyonları her ne kadar daha az olup, ppb seviyesinde ise de, bunların küresel 1sıtma faktörleri $\mathrm{CO}_{2} 1$ ise $\mathrm{CH}_{4} 28$ kat, $\mathrm{N}_{2} \mathrm{O} 265$ kat gibi oldukça yüksektir (IPCC-AR5, 2013). Bu gazların konsantrasyonları ile 1sıtma etki faktörleri çarpılır ve $\mathrm{CO}_{2}$ değerine eklenirse, efektif toplam konsantrasyon, 500 ppm CO $\mathrm{CO}_{2}$-eşdeğeri 'ni geçtiği görülebilir. Bu durumda küresel ısınmanın azalacağını beklemek, şimdilik hayaldir. Küresel emisyon artış hızını düşürmek için ve emisyonlar sürerken meydana gelecek olumsuzluklara uyum gösterebilmek için, pek çok araştırma yapılmaktadır ve elbet bu araştırmalar devam da etmelidir. Ancak ABD'nin yarı yoldan geri dönmesi kesinlikle hatadir.

İlk defa 1997 'de, Japonya-Kyoto'da COP 3 toplantısında Brezilya'nın teklifi ile "Tarihi Sorumluluk" kavramı kabul edilmiş ve ülkelerin toplam karbon salınımları 1750 yılından itibaren hesaplanmaya başlanmıştır. (17512007) y1lları arası tarihi sorumluluk payları, AB ülkeleri \% 30, ABD \% 27, Çin \% 9, Rusya \% 7, Japonya \% 4, Hindistan \% 3 olarak hesaplanmıştır. Aynı yıllar arası kişi başı salınım miktarları da, İngiltere 330, ABD 310, Almanya 270, Kanada 215, Rusya 180, Japonya 110 ton olarak bulunmuştur (Hansen, 2009). Daha detaylı bir başka sıralamada (1890-2000) yılları arası paylar, ABD \%19, AB \% 18, Latin Amerika Ülkeleri \%13, Eski Sovyet Ülkeleri \% 11, Çin \%10, Hindistan \% 7, Güney Doğu Asya Ülkeleri \% 6 şeklindedir (REC Türkiye, 2015). Bugün Çin'in emisyonu, $A B D$ ve $A B$ ikilisinin toplam emisyonunu geçiyor olsa da, küresel 1sınmanın baş sorumluları $(\mathrm{ABD}+\mathrm{AB})$ olduğu hesaplamalardan görülebilmektedir.

$\mathrm{Bu}$ gerçeğe rağmen $\mathrm{ABD}$ bugün kaya gazı üretimine hız vermiş, 2016 dünya doğal gaz ihracat şampiyonu Katar'ın önünü kesip, birinciliği ve dünya 
pazarlarını ele geçirmek ve de korkunç bütçe açıklarını kapatmak için, Orta Doğu'da akıl almaz siyasi oyunlara kalkışmıştır.

Bu gidişle küresel 1sınma azalacak gibi değildir. Daha önce verdiğimiz NASA rakamı, (1880-2016) yılları arasında küresel isınmanın 0,99 ${ }^{\circ} \mathrm{C}$ olduğudur. Yine yukarıda gösterdiğimiz IPCC -AR5'e göre, son dönemler

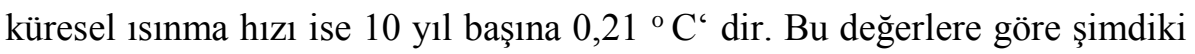
gidişle, küresel ısınma 2100 yılı sonunda yaklaşık olarak;

$$
0,99+[(2100-2016) / 10 \times 0,21]=0,99+(8,4 \times 0,21)=0,99+1,76=
$$
$2,75{ }^{\circ} \mathrm{C}$ bulunur.

Üstelik bu değer Trump' in kararıyla ABD'nin oyundan çıkması sonrası daha da artacaktır. IPCC' nin 4 ana senaryo ve yaklaşık 40 alt senaryo ile ortaya koyduğu tahminler 2 ile $4{ }^{\circ} \mathrm{C}$ arasında değişmektedir (IPCC AR5, 2013). Hâlbuki Paris İklim Anlaşması, hedefi 1,5 eğer tutturulamazsa maksimum $2{ }^{\circ} \mathrm{C}$ olarak belirlemiştir. Olabilir mi? Yukarıdaki basit hesaba göre bile, $2^{\circ} \mathrm{C}$ çok zor, fakat $1,5^{\circ} \mathrm{C}$ imkânsızdır. Şimdiden $1,5^{\circ} \mathrm{C}$ 'ye sadece $0,51{ }^{\circ} \mathrm{C}$ kalmış, hâlbuki 2100 yılına kadar daha 83 yıl var. Belki, petrol yaklaşık 40-50 y1l sonra gerçekten biterse ve tüm insanlık GES, RES, HES ve Hidrojen Enerji Sistemleri' ne geçerse bu durum mümkün olabilir. Her şeye rağmen elektrikli otomobil üreticisi Tesla, 2017 y1lı Haziran'ında, fosil yakıtlı araba üreticileri Ford ve Chrysler'i geçerek ABD'de en büyük otomotiv şirketi oldu. Almanya ise Mart 2017'de ülke enerjisinin ortalama \%40'ını yeşil kaynaklardan sağladı (Kurnaz, 2017). Evet, yine de 1şık var ve ümidimiz sürüyor.

\section{KAYNAKLAR}

AÇA, (2015). Avrupa Çevre Ajansı, Değişen Bir İklimde Yaşamak, Kopenhag https://www.eea.europa.eu/tr/publications/aca-isaretler-2015-degisen-bir adresinden alındı.

Erol, O. (2008). Genel Klimatoloji. 10.b, İstanbul: Çantay Kitabevi.

Hansen, J. E. (2009). Küresel Isınmanın Kırllma Noktası. İstanbul: Ayrıntı yayınları.

IPCC, (2001). Climate Change 2001- IPCC Third Assessment Report, https://www.ipcc.ch/ipccreports/tar/ adresinden alındı. 
IPCC, (2013). Climate Change 2013: The Physical Science Basis, Climate Change 2014 Synthesis Report, https://www.ipcc.ch/pdf/assessmentreport/ar5/syr/SYR_AR5_FINAL_full.pdf adresinden alınd1.

IPCC, Climate Change Synthesis Report, Fourth Assessment Report (AR4), 2007, http://www.ipcc.ch/publications_and_data/publications_ipcc_fourth_assessm ent_report_synthesis_report.htm Adresinden alınd1.

Karapınar, B. (2016). Su Yasası Şart, EKOIQ, 62,6.

Kurnaz, ML. (2017). Bir kez daha Paris Anlaşması. EKOIQ, 71,42-43.

REC Türkiye (2015). A'dan Z’ye İklim Değişikliği Başucu Rehberi.Ankara:

Ajanstürk Matbaacılık,

Şahin, E.G. (2017). Atmosferik Karbondioksit Seviyesinde Yeni Rekor. EKOIQ, 71, 70-72.

Şen, Z. (2009). İklim Değişikliği Tatlı Su Kaynakları ve Türkiye. İstanbul: Su Vakfı Yayınları.

URL-1, www.amerikaninsesi.com/a/Trump-Obamanın-çevre düzenlemelerini/, (Erişim Tarihi: 28 Mart 2017).

URL-10, www.nasa.gov/press -release /nasa-noaa-data-show-2016-warmest-/, (Erişim Tarihi: 18 Ocak 2017)

URL-11, http://newatlas.com/before-after-photos-glaciers-climatechange/49143/\#gallery

URL-12, https://www.epa.gov/climate-indicators/climate-change-indicators-glaciers,

URL-13, www.hurriyet com.tr/buzullar-eridi-ada-ortaya-çıktı/, (Erişim Tarihi: 18 Ocak 2017)

URL-14, www.dw.com/tr/batan adalar, (Erişim Tarihi: 19 Mayıs 2017).

URL-15, http://www.demokrathaber.org/cevre/deniz-seviyesi-yükselmesi-sonucupasifikte-5/, (Erişim Tarihi:18 Mayıs 2016),

URL-16, http://www.haberturk.com/yerel-haberler/haber/45602065-5-hazirandunya-cevre/, (Erişim Tarihi:18 Mayıs 2016),

URL-17, http://www.tema org.tr/web_14966-2_1/, (Erişim Tarihi: 24 Temmuz 2017), 
URL-2, www.milliyet.com.tr/ab-ve-çin-abd-ye-karş1-birleşti-dünya-2460720/, (Erişim Tarihi: 1 Haziran 2017).

URL-3, www.hidropolitikakademi.org/tr/trumpin-iklim-beyanına-dair/, (Erişim Tarihi: 4 Haziran 2017)

URL-4, https://medium.com/@dokuz8HABER/abd-baskanı-trumpın-paris-iklim, (Erişim Tarihi: 5 Haziran 2017)

URL-5, www.bbc.com/turkce/haberler/2014/05/140519/_antarktika, (Erişim Tarihi: 19 Mayıs 2017).

URL-6, https://www.esrl.noaa.gov/gmd/ccgg/trends/global.html\#global_growth.

URL-7, https://climate.nasa.gov/vital-signs/global-temperature/

URL-8, https://www.co2.earth/global-warming-update/, (Erişim Tarihi: 20 Temmuz 2017).

URL-9, www.ncdc.noaa.gov/sotc/global/201613/, (Erişim Tarihi:19 Ocak 2017). 